\title{
Perancangan Aplikasi Penyisipan Pesan pada File Mp3 menggunakan Metode Parity Coding dan Enkripsi Caesar Cipher
}

\author{
Hery Setyo Putranto ${ }^{1}$, Citra Kurniawan ${ }^{2}$ \\ Sekolah Tinggi Teknik Malang \\ herisetyo71@gmail.com ${ }^{1}$ \\ airakurniawan@gmail.com²
}

\begin{abstract}
The science of hiding messages in a media is an interesting science to learn. Inserting messages either in text, image, sound and video messages requires input in the form of digital files that will be inserted messages, messages to be inserted (message), and keys (keys). More MP3 are chosen for use than using image files. In hiding messages, a format that is more common is used will be chosen so as not to cause excessive suspicion. Encryption is very important in cryptography, is the security of the data sent to maintain its confidentiality. The type of data in writing this report is the data obtained from the literature study to obtain theoretical data that is used as supporting literature to support the research conducted. The source of the data obtained is primary data as a reference, in this case the author gets data from previous researchers that are related to the research that the author did. The steganography method used in this research is parity coding, which is inserting messages / information into the carrier media in the form of MP3 audio files by first being encrypted using cipher caesarean cryptography encryption technique, which is an algorithm with substitution techniques where each letter in the bright text (plaintext ) replaced by another letter that has a certain position difference in the alphabet. This research was made using Visual Basic.Net software. The results of this study in the form of data that has been encrypted using caesar cipher method and hidden into MP3 Audio File then extracted to get text messages and decrypted to get the original message contained in the mp3 file.
\end{abstract}

Keywords: Message Insertion Application, Parity Coding, Caesar Chiper.

\section{PENDAHULUAN}

Seiring perkembangan teknologi saat ini yang semakin pesat, maka proses pengiriman data dapat dilakukan dengan mudah dan melalui berbagai macam media yang ada. Seperti media internet dengan fasilitas e-mail, transfer data antar perangkat mobile hingga mengunakan jaringan komputer. Teknik menjaga kerahasiaan pesan tidak hanya dengan menggunakan kriptografi. Ada teknik lain yang sudah digunakan sejak berabad-abad lalu, yaitu steganografi. Perkembangan yang begitu pesat dalam proses pengiriman data membawa dampak yang sangat besar, yaitu masalah keamanan data yang dikirim. Maka dari itu, tidak mungkin mengirim data melalui media-media tersebut secara polos, melainkan harus dilakukan proses pengamanan untuk data atau informasi diantaranya menggunakan metode kriptografi dan steganografi. Ilmu menyembunyikan pesan dalam suatu media, merupakan ilmu yang menarik untuk dipelajari. Steganografi sudah ada sejak zaman dahulu, namun masih berkembang hingga sekarang. Perkembangan teknik steganografi tentunya tidak terlepas dari peran teknologi informasi, karena dengan penggunaan teknologi informasi membuka lebih banyak kemungkinan dimana suatu pesan dapat disembunyikan, misalnya dalam sebuah file. Salah satu hal yang memicu perkembangan teknik steganografi 
adalah penyerangan steganalis yang berhasil memecahkan pesan yang disembunyikan menggunakan metode steganografi yang sudah banyak dikenal.

\section{TINJAUAN PUSTAKA}

\begin{tabular}{ccc}
\multicolumn{2}{c}{ Metode Parity } & Coding \\
merupakan salah satu metode
\end{tabular} Steganografi yang cukup populer, setelah metode Low Bit Encoding, tetapi memiliki kelebihan dari segi keamanan yang ditawarkan. Menurut Herianto (2009), Pada metode ini, sinyal media yang sudah diencode akan dibagi menjadi beberapa bagian (region) terpisah dengan ukuran statis. Parity bit dari setiap region akan dihitung terlebih dahulu untuk disimpan nilainya. Bit dari pesan rahasia akan disisipkan secara merata kedalam region nilainya berbeda, maka susunan dari bit-bit LSB harus diubah sedemikian rupa sehingga parity bit region nilainya sama dengan bit pesan rahasia yang akan disisipkan namun jika nilainya sama region tidak perlu diubah. Kondisi dalam penghitungan parity bit adalah even parity.

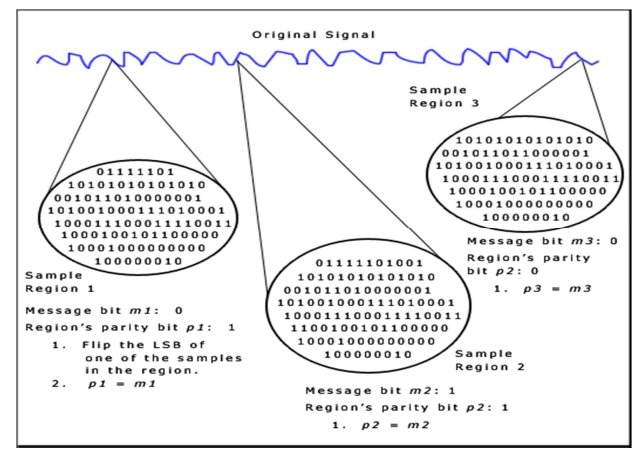

Gambar 1 Penyembunyian pesan dengan Parity Coding (Sumber: Herianto, 2009)

Dalam proses ekstraksi, pesan rahasia adalah nilai-nilai parity bit dari setiap region. Parity bit ini akan disusun kembali membentuk pesan rahasia yang sudah disisipkan. Region yang terbentuk akan sama seperti penyusunan karena menggunakan kunci yang sama (Herianto, 2009).
Hal ini mendorong keinginan untuk mencari metode alternatif dalam penyembunyian pesan yang tidak pernah terpikirkan sebelumnya.

Dalam kriptografi, sandi Caesar, atau sandi geser, kode Caesar atau Geseran Caesar adalah salah satu teknik enkripsi paling sederhana dan paling terkenal. Sandi ini termasuk sandi substitusi dimana setiap huruf pada teks terang (plaintext) digantikan oleh huruf lain yang memiliki selisih posisi tertentu dalam alfabet. Misalnya, jika menggunakan geseran 3 , W akan menjadi Z, I menjadi L, dan $\mathrm{K}$ menjadi $\mathrm{N}$ sehingga teks terang "wiki" akan menjadi "ZLNL" pada teks tersandi. Nama Caesar diambil dari Julius Caesar, jenderal, konsul, dan diktator Romawi yang menggunakan sandi ini untuk berkomunikasi dengan para panglimanya (Nicolas, 2014).

Tabel 1 Algoritma ROT3

\begin{tabular}{|c|c|}
\hline Plain Text & $\begin{array}{c}\text { Encoded } \\
\text { Text }\end{array}$ \\
\hline ABC & DEF \\
\hline Hello & Khoor \\
\hline Attack & Dwwdfn \\
\hline
\end{tabular}

(Sumber: Ariyus, 2008: 50)

Subtitusi kode yang pertama dalam dunia persandian terjadi pada pemerintahan Yulius Caesar dikenal dengan kode kaisar (Caesar Chiper), yakni menggantikan posisi huruf awal dari alphabet atau disebut juga dengan algoritma ROT3. Jika penggeseran yang dilakukan sebanyak tiga kali, maka kunci untuk dekripsinya adalah 3 (Ariyus, 2009: 35). Penggeseran kunci yang dilakukan tergantung pada keinginan si pengirim pesan. Bisa saja kunci yang dipakai $a=7, b=9$, dan seterusnya.

\section{METODE PENELITIAN}

Penelitian yang berjudul "Perancangan Aplikasi Penyisipan Pesan Pada File MP3 Menggunakan Metode 
Parity Coding Dan Enkripsi Caesar Cipher" menggunakan jenis metode penelitian dan pengembangan (Research and Development atau R\&D). Penelitian dan Pengembangan atau Research and Development (R\&D) adalah rangkaian proses atau langkahlangkah dalam rangka mengembangkan suatu produk baru atau menyempurnakan produk yang telah ada agar dapat dipertanggung jawabkan. Sumber data yang digunakan pada penelitian ini adalah data primer dan data sekunder. Data primer adalah data sebagai referensi yang diperoleh langsung dari tangan pertama, dalam hal ini penulis mendapatkan data dari peneliti sebelumnya yang terkait dengan penelitian yang penulis lakukan. Data primer adalah Data yang diperoleh berasal dari sumber yang sudah ada seperti jurnal, buku, website. Data yang dikumpulkan dalam penelitian ini merupakan data sekunder. Data diperoleh dari telaah pustaka dan dokumen yang didapat penulis dari pustaka yang mendukung, informasi dari internet, buku-buku dan artikel dari jurnal.

\section{HASIL DAN PEMBAHASAN}

Penelitian ini dilakukan menggunakan file audio dan format file audio yang digunakan hanya mp3. Kunci yang digunakan sebagai pengaman pesan adalah kunci standart enkripsi caesar chiper $\mathrm{k}=3$ atau dapat diubah sesuai keinginan. Algoritma dalam penelitian ini adalah Algoritma Parity Coding dan Caaesar Cipher. Software implementasi yang digunakan adalah Visual Basic 2012. Dalam penelitian ini diperoleh hasil pengujian, terbukti bahwa aplikasi yang sudah dibuat telah berhasil menjalankan proses penyisipan dan ekstraksi pesan dengan baik. Semua pesan berhasil disisipkan dan diekstraksi dengan baik. Apabila data teks yang disisipkan ke dalam file mp3 semakin banyak, maka akan mempengaruhi kualitas file mp3 tersebut.

\section{ALUR APLIKASI PENYISIPAN PESAN DAN ENKRIPSI}

Pada gambar dibawah ini akan dijelaskan mengenai alur perancangan
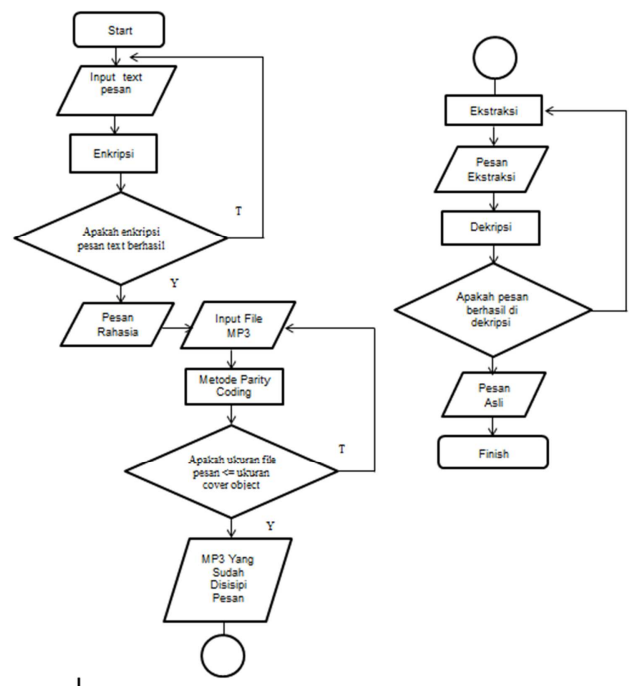

sistem secara menyeluruh:

\section{Gambar 2 Flowchart Aplikasi}

Pada alur sistem aplikasi ini langkah pertama untuk menginput pesan teks asli ke dalam aplikasi. Setelah menginput file pesan di enkripsi menggunakan teknik Caesar Cipher. Selanjutnya hasil dari file yang sudah di enkripsi berbentuk chipertext. Memasukkan file audio MP3 ke dalam aplikasi. Setelah proses enkripsi selesai dilakukan, proses berikutnya adalah penyisipan pesan menggunakan metode parity coding. Hasil dari penyisipan pesan menggunakan metode parity coding berbentuk stego file. Proses pengambilan data rahasia, yaitu melakukan ekstraksi menggunakan metode parity coding. Hasil dari proses ekstraksi dengan parity coding. Proses mendeskripsikan kembali agar bisa mendapatkan isi yang sebenarnya. Isi dari file yang sebenarnya atau plaintext.

\section{DESIGN INTERFACE APLIKASI}

\section{Menu Utama}

Menu utama pada Aplikasi Penyisipan Pesan pada File MP3 menggunakan Metode Parity Coding 
dan Enkripsi Caesar Cipher ini adalah menu yang akan mengarahkan user pada menu informasi dan menu steganografi

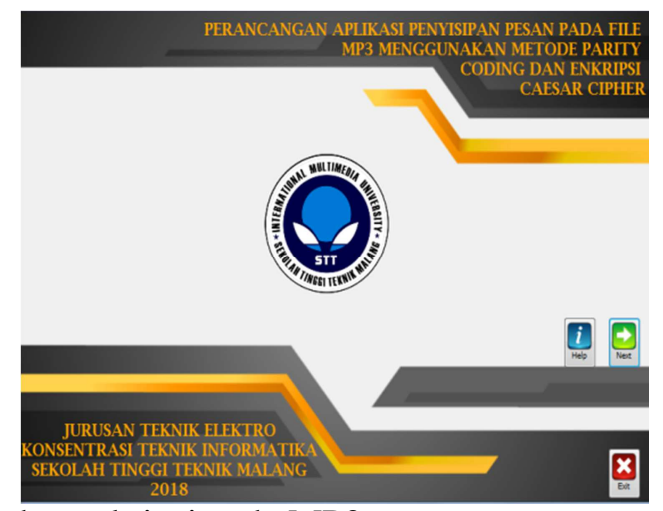

dan enkripsi pada MP3.

\section{Gambar 3 Tampilan Menu Utama}

(Sumber: Peneliti)

Menu utama pada aplikasi ini berisi button help untuk masuk menu informasi ,button next untuk masuk menu steganografi dan enkripsi mp3 dan button exit untuk keluar dari aplikasi.

\section{Menu Help}

Menu Help adalah menu yang berisi informasi tentang karateristik file yang digunakan, judul penelitian dan identitas peneliti. Menu Help menggunakan satu button untuk kembali ke menu utama.

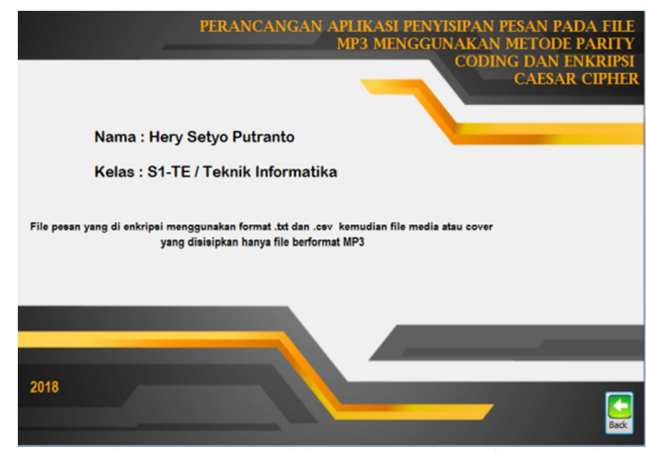

Gambar 4 Tampilan Menu Informasi

Menu utama pada aplikasi penyisipan pesan pada file $\mathrm{mp} 3$ menggunakan metode parity coding dan enkripsi caesar cipher pada ini berisi Menu Help atau informasi menggunakan satu button untuk kembali ke menu utama.

\section{Menu Penyisipan Pesan}

Menu penyisipan pesan adalah sebuah menu yang berisi tentang proses penyisipan pesan pada file mp3 yang terdiri dari listbox teks pesan berfungsi untuk mengetahui letak file pesan, button buka pesan yang berfungsi untuk mengambil file pesan dan otomatis proses enkripsi, listbox pesan asli dan hasil enkripsi caesar chiper berfungsi untuk menampilan pesan asli dan pesan chiper, listbox file mp3 berfungsi untuk mengetahui letak file mp3, button buka file mp3 berfungsi untuk mengambil file $\mathrm{mp} 3$, listbox folder penyimpanan befungsi untuk mengetahui letak file di simpan, button simpan data berfungsi untuk memilih letak file mp3 yang sudah disisipkan pesan berada di folder apa, listbox key berfungsi untuk memasukkan kunci dari file mp3 yang sudah disisipkan pesan, button mulai proses berfungsi untuk melakukan proses penyisipan, listbox file mp3 steganografi berfungsi untuk mengetahui letak file mp3 steganografi, button play, pause dan stop berfungsi untuk memutar musik, jeda dan menghentikan musik.

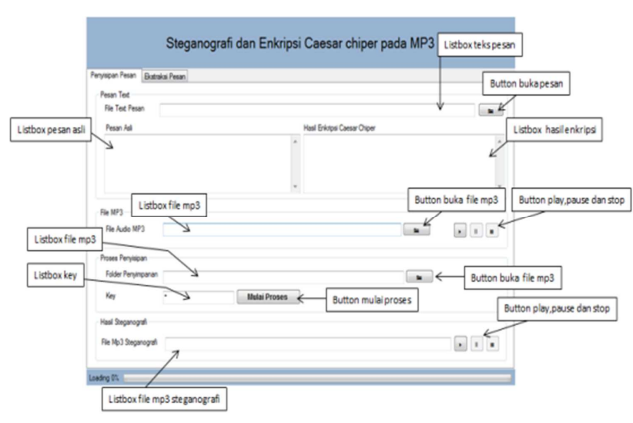

Gambar 5 Tampilan Menu Penyisipan Pesan (Sumber: Peneliti)

\section{Menu Ekstraksi Pesan}

Menu ekstraksi pesan adalah sebuah menu yang berisi tentang melakukan proses ekstraksi agar pesan di dalam mp3 dapat di ambil kembali dan di dekripsi menjadi pesan asli, terdiri dari listbox stegano file berfungsi untuk mengetahui letak file stegano, button buka stegano file berfungsi untuk membuka file stegano mp3, button play, pause dan stop berfungsi untuk 
mendengarkan file stegano mp3, listbox kunci berfungsi untuk memasukkan kembali kunci yang sama ketika enkripsi, button proses berfungsi untuk melakukan ekstraksi dan dekripsi agar file asli dapat diperoleh kembali, listbox pesan asli berfungsi untuk mengatahui proses dekripsi berhasil atau tidak.

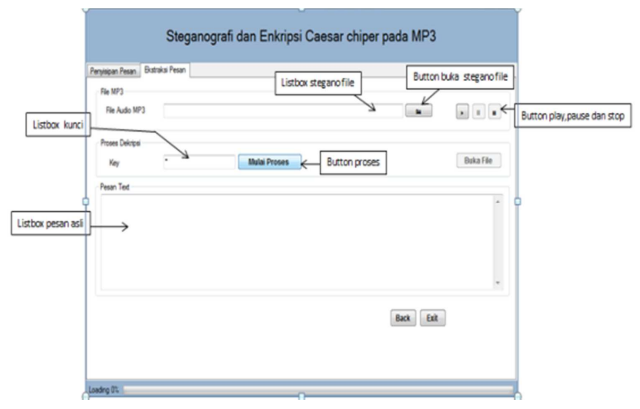

Gambar 6 Tampilan Menu Ekstraksi Pesan (Sumber: Peneliti)

\section{KESIMPULAN}

Bedasarkan hasil penelitian yang telah dilakukan maka diperoleh kesimpulan sebaga berikut ini :

1. Proses enkripsi pada pesan yang akan disipkan menggunakan metode Caesar cipher dibuat menggunakan visual basic.net

2. Setelah melakukan proses embedding(penyisipan pesan), terdapat penurunan kualitas dari stegano file jika dibandingkan dengan file MP3 yang asli, karena terjadi proses penggantian nilai bit terakhir dari setiap karakter file media dengan kemungkinan perubahan sebesar $50 \%$.

3. Ukuran file pesan berpengaruh pada hasil suara dari steganofile. Semakin besar ukuran file pesan, maka kualitas suara semakin menurun.

4. Proses embedding tidak mengembalikan file MP3 ke kualitas aslinya.

\section{DAFTAR RUJUKAN}

Afghan, Amar. 2008. Pengembangan Web E-Commerce Bojana Sari Menggunakan Metode Prototype Jurnal. Sistem Informasi, Universitas Telkom
Ariyus Dony, 2009. Keamanan Multimedia. Andi: Yogyakarta

Ariyus Dony, 2008. Pengantar Ilmu Kriptografi. Stmik Amikom Yogyakarta . Andi: Yogyakarta

Arlando, Riko. 2006, Metode Parity Coding versus Metode Spread Spectrum Pada Audio Steganography. Jurnal. Teknik Elektro, Universitas Kristen Maranatha

Azwar, Rizky. 2013, Perancangan Aplikasi Penyisipan Data Pada Audio Dengan Menggunakan Metode Low Bit Coding. Jurnal. Teknik Informatika, STIMIK Budidarma Medan

Batara, Simon. 2006, Studi Steganografi Dalam File MP3. Jurnal. Teknik Informatika, Institut Teknologi Bandung

Bobsusanto. 2016. 12 Pengertian Aplikasi Menurut Para Ahli Lengkap (Online). (http://www.sepengetahuan.com /2016/06/10-pengertian-aplikasimenurut-para-ahli-lengkap.html, diakses 7 Mei 2018)

Anggarini, DC \& Citra Kurniawan. 2017. Perancangan Aplikasi Algoritma Aes Rijndael Pada Enkripsi Citra Digital File Jpeg 128 Bit. Sinteks: Jurnal Teknik. Sekolah Tinggi Teknik Malang

Fathul, Galih \& Insanudin Entik. 2006. Implementasi Algoritma Chiper Caesar Untuk Enkripsi Dan Dekripsi Pada Tabel Ascii Menggunakan Bahasa Java Dokumen Elektronik. Jurnal. Teknik Informatika, UIN Sunan Gunung Djati Bandung

Herianto. 2009, Pembangunan Perangkat Lunak Steganografi Audio MP3 dengan Teknik Parity Coding pada Perangkat Mobile Phone. Tugas Akhir. Teknik 
Informatika, Institut Teknologi Bandung

Jaya, Indra, 2017, Analisis Teknik Steganografi Pada Audio MP3 Menggunakan Metode Parity Coding Dan Enkripsi Cipher Transposition. Jurnal. Sistem Informasi Dan Komputer, STMIK Bina Mulia Palu

Komputer, Wahana. 2012. Visual Basic 2010 Programming. Yogyakarta : Andi Offset.

Kuncara, Purba. 2017. Macam-macam Format File Audio Beserta Kelebihan dan Kekurangan (Online).

(https://klikhost.com/macammacam-format-file-audiobeserta-kelebihan-dankekurangan/, diakses 21 Mei 2018)

Riadi, Muchlisin. 2014. Pengertian, Sejarah dan Jenis Kriptografi (Online).

(https://www.kajianpustaka.com /2014/01/pengertian-sejarahdan-jenis-kriptografi.html /, diakses 8 Mei 2018)

Septi, 2015. Perancangan Aplikasi Bisnis (Online). (http://elib.unikom.ac.id/files/dis k1/653/jbptunikompp-gdlteddysepti-32644-10-unikom_ti.pdf, diakses 14 Mei 2018)

Sholihin, Ibnu Ubaydillah. 2015. Pengertian Instrumen Penelitian (Online).

(http://www.zakymedia.com/20 15/04/pengertian-instrumenpenelitian.html, diakses 20 Juni 2018)

Sulistyanto, Agung. 2016, Digital Watermarking Pada Citra Menggunakan Metode Modified Least Significant Bit (MLSB) Dengan Penyebaran Pesan Secara Acak Menggunakan Metode Linear Congruential
Generator(LCG):Studi

Laboratorium ICT Terpadu.

Tugas Akhir. Teknik Informatika, Universitas Budi Luhur 